\title{
Different levels of physical activity and anthropometric profile in patients infected with hepatitis $C$ virus
}

\author{
Lucas de Lucena de Simões ${ }^{1}$, Eline Autran de Lima², Gabriela Carvalho Jurema Santos ${ }^{3}$, \\ Tafnes Oliveira ${ }^{3}$, Elenilson Maximino Bernardo ${ }^{5}$, Luana Olegário ${ }^{3}$, Erika Rabelo Fortes Siqueira 4 , \\ Matheus Santos de Sousa Fernandes ${ }^{1}$
}

${ }^{1}$ Department of Gastroenterology (LIM 07), University of São Paulo School of Medicine; ${ }^{2}$ School of Physical Education, University of Pernambuco; ${ }^{3}$ Department of Nutrition, Federal University of Pernambuco; ${ }^{4}$ Division of Gastroenterology and Hepatology, Department of Gastroenterology, University of Pernambuco; ${ }^{5}$ Federal University of Pernambuco

\section{Summary}

Study aim: To verify the relationship between different durations of regular practice of physical activity in aspects related to the anthropometric profile and hepatic function of patients infected by hepatitis $\mathrm{C}$ virus (HCV).

Material and methods: 125 patients (aged $55.2 \pm 10.4$ years) participated in the study. Clinical data were obtained through medical records available at the Pernambuco Liver Institute. Physical activity levels were obtained through the International Physical Activity Questionnaire (IPAQ) short form to classify the patients according to the guidelines of the American College of Sports Medicine (ACSM).

Results: Significant differences were found in GGT 141 (28-378 U/L) and HDL 39 (27-56 mg/dL) respectively in insufficiently active and physically active groups, AST 71 (26-268 U/L), ALT 83 (36-452 U/L), GGT 78 (3-532 U/L), alkaline phosphatase $74(47-302 \mathrm{mg} / \mathrm{dL})$ and total bilirubin $0.7(0.1-2.8 \mathrm{mg} / \mathrm{dL})$ in insufficiently active and very physically active groups. Anthropometric data showed significant differences in chest $(\mathrm{p}<0.01)$, abdomen $(\mathrm{p}<0.02)$ and waist measurement $(\mathrm{p}<0.01)$ between insufficiently active and very physically active groups.

Conclusion: Physical activity, when practiced regularly for more than 300 minutes per week, can improve the clinical and anthropometric profile in patients infected with $\mathrm{HCV}$.

Key words: Lifestyle modification - Hepatitis C - Physical activity - Liver - Health

\section{Introduction}

Hepatitis $\mathrm{C}$ virus infection is a public health problem affecting about 170-200 million people around the world. The physiopathological features are related to inflammation and deposition of collagen type I within the hepatic extracellular matrix, which characterizes the process of fibrosis $[20,22]$. The hepatitis $C$ virus causes several morbidities in the host organism, and has a great evolutionary potential for other conditions such as cirrhosis and hepatocellular carcinoma (HCC), which is the main causes of liver transplants in the world [28]. In addition, progression of $\mathrm{HCV}$ is affected by several factors (duration of disease, age at infection, gender, coinfection with inflammatory viruses and immunogenetic background) and viral (genotype, viral load, pathogenicity of viral isolate) [13].

Sedentary lifestyle and disordered eating habits directly influence the distribution of body fat [12]. Thus, the patient has a double impairment since the hepatitis $C$ virus uses hepatocytes for its replication and when allied to the infiltration of fat in the liver compromises its functionality by the inflammatory pathway and parameters related to hepatic fibrosis. Regarding methods of evaluation of body fat distribution, anthropometric measures have been widely used in other areas to evaluate these corporal features. Most studies use a moderate intensity pattern with a frequency of three days per week to generate benefits in the hepatic condition of patients infected with $\mathrm{HCV}$ $[1,7]$. Through this method, it is possible to obtain information about the presence of body fat and its distribution. 
In addition, these measures are also used to verify the risk of developing cardiovascular diseases, such as stroke and hepatic steatosis, and increased mortality in patients with hepatitis C [21].

Several studies have demonstrated that regular physical activity practice in different modalities (aerobic or resistance) can generate significant benefits in the liver $[6,7$, $8,11]$. In addition, it is known that moderate to vigorous physical activity can cause positive immune regulation, decreasing the expression of pro-inflammatory cytokines and reactive oxygen species [19].

Few studies have directly evaluated the effects of AF and the anthropometric profile on the clinical and health staging of patients with $\mathrm{C}$ virus, which provides originality to the present study. In addition, the understanding of how such variables can modulate healthy behavior seems to be relevant for health promotion programs and clinical practice. Therefore, to understand how these tools (physical activity and anthropometric measures) can be used to improve the clinical condition of these patients, the objective of the present study is to verify the relationship between different durations of regular practice of physical activity in aspects related to the anthropometric profile and hepatic function of patients infected by HCV.

\section{Material and methods}

\section{Sample}

125 patients $(55.2 \pm 10.4)$ participated in the present study. This is a quantitative approach and descriptive cross-sectional study with comparison of groups. The sample consisted of patients of both genders, over 18 years of age, infected by the hepatitis $\mathrm{C}$ virus, who attended for at least 1 year the Institute of Liver and Transplantation of Pernambuco (IFP). Subjects included in this study had positive anti-HCV, HCV-RNA reagent and signed the informed consent form. Subjects with co-infection such as HBV, HIV, HTLV, alcohol consumption or those who did not clearly report daily physical activities and other information were excluded

\section{Study groups}

After obtaining physical activity data, the patients were divided into three different groups, according to their respective time spent in physical activity: insufficiently active (G1), physically active (G2) and very physically active (G3).

\section{Physical activity levels and clinical data}

In the first contact with the patient, a clinical questionnaire was used to obtain sociodemographic information (name, sex, age, date of birth, etc.). Clinical and laboratory data were obtained through medical records available at the IFP. This center has a significant database with a description of all the clinical and sociodemographic characteristics of the patients. In addition, it serves around 900 patients monthly, consolidating itself with one of the largest centers in Brazil for the treatment of liver diseases. Physical activity levels were obtained through the International Physical Activity Questionnaire (IPAQ) short form. To classify the patients in their respective group, we used the guidelines of the American College of Sports Medicine (ACSM) [10]. This questionnaire classifies physical activity based on the frequency, intensity and duration of the exercise, and is divided into three categories: insufficiently activity, moderate activity and high activity. The group considered as "insufficiently active" consisted of patients who did not reach 150 minutes of physical activity per week. The "physically active" group consisted of patients classified as having moderate activity and time spent between 150 and 300 minutes per week, and the "very physically active" group was classified as having high activity, consisting of patients who practice more than 300 minutes of physical activity per week. The IPAQ shows validity and reproducibility for the Brazilian population [16].

\section{Anthropometric measures}

To obtain the anthropometric data, we used a measuring tape with resolution of 0.5 centimeters. The following measurements were obtained: body height and body weight to calculate the body mass index (BMI), right arm, chest, waist, abdomen, hip, waist-to-hip ratio and waistto-height ratio. Only one researcher previously trained to avoid data inconsistency obtained the measures. All the procedures were performed according to the International Society of Advanced Kinanthropometry (ISAK) [17].

Procedures and ethics

All the questionnaires and procedures used in the study were explained in detail to the patients, avoiding any embarrassment and directing them to provide the data with clarity, precision and objectivity. The study was approved by the Ethics Committee with the CAAE: 48823015.3.0000.5192, according to resolution 466/12 of studies with human beings.

\section{Statistical analysis}

The data are given as means $\pm \mathrm{SD}$ (standard deviation) when parametric and median (minimum-maximum) when non-parametric. The D'Agostino-Pearson test was used to verify the Gaussian distribution. The comparison between groups was carried out using the Mann-Whitney test if the data were not normally distributed and the $t$-test for normal distribution. Differences were considered significant when $\mathrm{p}<0.05$. For all the analyses, we used the software GraphPad Prism v 6.0. 


\section{Results}

In the comparisons between the insufficiently active group and the physically active group, significant differences were observed for GGT $(p<0.01)$ and HDL $(p<0.02)$. In the comparative analyses with the active and very physically active groups, significant differences were observed for AST ( $p<0.04)$, ALT $(p<0.04)$, GGT $(\mathrm{p}<0.004)$ alkaline phosphatase $(\mathrm{p}<0.02)$ and total bilirubin $(\mathrm{p}<0.02)$. Table 1 shows the characteristics of the study population according to different levels of physical activity.

Regarding the anthropometric data (Table 2), significant differences were observed for chest $(p<0.01)$, abdomen $(p<0.02)$ and waist measurement $(p<0.01)$ for comparisons between the groups of insufficiently active and very physically active patients.

\section{Discussion}

Our study demonstrated that patients with a higher level of PA obtained a better condition in relation to biochemical and anthropometric indicators, providing a better clinical condition and fulfilling the objective of the present study.

Lifestyle factors can modulate the risk of developing several chronic diseases. Independent of dietary habits, it is observed that the risk of developing chronic disease in the sedentary population is increased while in patients who are considered physically active it is decreased. The clinical association in several morbidities such as obesity, hypertension, diabetes mellitus and cardiovascular diseases is clear in relation to the benefits of regular practice of physical activity. However, within the spectrum of

Table 1. Characteristics of study population according to different levels of physical activity

\begin{tabular}{lcccccc}
\hline & $\begin{array}{c}\text { Insufficiently } \\
\text { active }(\mathrm{n}=22)\end{array}$ & $\begin{array}{c}\text { Physically active } \\
(\mathrm{n}=25)\end{array}$ & $\begin{array}{c}\text { Very physically active } \\
(\mathrm{n}=78)\end{array}$ & $p$ & $p^{*}$ & $p^{* *}$ \\
\hline Clinical data & & & & & & \\
\hline Age [years] & $58.43 \pm 11.33$ & $53.24 \pm 11.87$ & $54.95 \pm 9.59$ & 0.30 & 0.31 & 0.51 \\
Blood glucose [mg/dL] & $97(67 \div 137)$ & $88(76 \div 201)$ & $91(63 \div 184)$ & 0.14 & 0.56 & 0.13 \\
Diabetes mellitus & $13.04 \%$ & $12.0 \%$ & $12.82 \%$ & & & \\
Hypertension & $60.86 \%$ & $36.0 \%$ & $46.15 \%$ & & & \\
\hline Laboratory data & & & & & & \\
\hline AST (U/L) & $71(26 \div 268)$ & $59(16 \div 248)$ & $44(17 \div 327)$ & 0.26 & 0.45 & 0.04 \\
ALT (U/L) & $83(36 \div 452)$ & $64(7 \div 313)$ & $59(13 \div 487)$ & 0.23 & 0.70 & 0.04 \\
GGT (U/L) & $141(28 \div 378)$ & $78(3 \div 532)$ & $70(10 \div 498)$ & 0.01 & 0.54 & 0.004 \\
Triglycerides [mg/dL] & $107(73 \div 231)$ & $90(47 \div 172)$ & $108(42 \div 356)$ & 0.21 & 0.19 & 0.89 \\
Total cholesterol [mg/dL] & $163.3 \pm 33.9$ & $171.9 \pm 27.0$ & $162.9 \pm 41.4$ & 0.82 & 0.21 & 0.95 \\
HDL [mg/dL] & $39(27 \div 56)$ & $53(21 \div 93)$ & $44(21 \div 106)$ & 0.02 & 0.25 & 0.09 \\
LDL [mg/dL] & $98.4 \pm 37.4$ & $96.3 \pm 23.7$ & $94.9 \pm 33.6$ & 0.82 & 0.15 & 0.33 \\
Alpha-fetoprotein [mg/dL] & $4.2(1.2 \div 22.3)$ & $3.7(1.2 \div 25.8)$ & $3.9(0.6 \div 39.0)$ & 0.85 & 0.97 & 0.78 \\
Alkaline phosphatase [mg/dL] & $99(45 \div 236)$ & $74(47 \div 302)$ & $71(12 \div 363)$ & 0.17 & 0.33 & 0.02 \\
Total bilirubin [mg/dL] & $0.8(0.3 \div 2.9)$ & $0.7(0.1 \div 2.8)$ & $0.6(0.1 \div 3.8)$ & 0.37 & 0.44 & 0.02 \\
\hline
\end{tabular}

AST: aspartate aminotransferase; ALT: alanine aminotransferase; GGT: gamma glutamyltransferase; HDL: high-density lipoprotein LDL: low-density lipoprotein $p$-comparison between insufficiently active and physically active; $p^{*}$ - comparison between physically active and very physically active; $p^{* *}$ : comparison between insufficiently active and very physically active; $p<0.05, \div-$ Interval related to the values of maximum and minimum scores 
Table 2. Anthropometric data of study population according to different physical activity levels

\begin{tabular}{lcccccc}
\hline & $\begin{array}{c}\text { Insufficiently active } \\
(\mathrm{n}=22)\end{array}$ & $\begin{array}{c}\text { Physically active } \\
(\mathrm{n}=25)\end{array}$ & $\begin{array}{c}\text { Very physically active } \\
(\mathrm{n}=78)\end{array}$ & $p$ & $p^{*}$ & $p^{* *}$ \\
\hline BMI & $26.1(20.4 \div 38.4)$ & $24.6(19.1 \div 40.9)$ & $25.2(17.1 \div 35.6)$ & 0.55 & 0.72 & 0.57 \\
Arm $[\mathrm{cm}]$ & $31.1 \pm 4.9$ & $30.92 \pm 4.8$ & $29.38 \pm 3.5$ & 0.67 & 0.70 & 0.67 \\
Chest $[\mathrm{cm}]$ & $99.9 \pm 11.9$ & $97.4 \pm 10.1$ & $95.4 \pm 9.0$ & 0.46 & 0.30 & 0.01 \\
Abdomen $[\mathrm{cm}]$ & $102(77.5-128)$ & $98.0(69-125)$ & $93(75-122)$ & 0.17 & 0.35 & 0.02 \\
Hip $[\mathrm{cm}]$ & $102.9 \pm 12.1$ & $102.1 \pm 12.9$ & $101.7 \pm 10.0$ & 0.84 & 0.45 & 0.49 \\
Waist $[\mathrm{cm}]$ & $100.8 \pm 14.9$ & $96.1 \pm 14.0$ & $93.4 \pm 11.3$ & 0.40 & 0.35 & 0.01 \\
Waist-to-hip ratio & $0.97 \pm 0.11$ & $0.94 \pm 0.11$ & $0.92 \pm 0.09$ & 0.71 & 0.46 & 0.05 \\
Waist-to-height ratio & $0.59 \pm 0.08$ & $0.58 \pm 0.08$ & $0.57 \pm 0.07$ & 0.74 & 0.29 & 0.19 \\
\hline
\end{tabular}

BMI: body mass index; $p$ - comparison between insufficiently active and physically active; $p^{*}-$ comparison between physically active and very physically active; $p^{* *}$ - comparison between insufficiently active and very physically active; $p<0.05$, $\div-$ Interval related to the values of maximum and minimum scores.

HCV infection, such benefits remain scarce. In our study, the mean age was similar in all physical activity groups (Table 1). With advancing age, the onset and development of chronic diseases and metabolic syndrome are increased. The emergence of these comorbidities allied to HCV infection causes a double impairment in health condition since the virus causes damage in the hepatocytes due to their replication activity [18]. These benefits are caused by the ability of the physical activity to positively modulate the metabolic profile by several factors, among which is the increase in aerobic capacity that helps avoid immune and energetic dysfunctions and decreases the susceptibility to associated diseases such as non-alcoholic fatty liver disease, which is commonly found in patients infected with hepatitis $C$ virus $[4,26]$.

Liver enzymes are widely used in clinical practice to provide important information about the health condition of the liver. Increased values of these enzymes are related to the progression and severity of $\mathrm{HCV}$ infection. In the present study, significant differences were found in AST $(p=0.04)$ and ALT $(p=0.04)$ in the comparative analyses of the insufficiently active group and the very physically active group, showing that when exposed to regular practice of physical activity, HCV infected patients have decreased liver damage. In the GGT analyses, we found two significant differences. The first was in comparison of insufficiently physically active and very physically active groups $(p=0.01)$, and the second was in comparison of the insufficiently active and very physically active groups $(\mathrm{p}=0.004)$.

GGT levels, associated with sedentary behavior, have been reported as one of the predictors of diabetes mellitus [24]. In addition, the regular practice of physical activity can regulate the values of this transaminase [25]. Our results show that when the patients modify their sedentary state to a physically active condition, benefits related to the maintenance of liver damage and regular physical activity practice are obtained. Moreover, when there is a double increase in the time spent in weekly physical activities, there seems to be a double improvement in the clinical status. However, for these improvements to be obtained, one must maintain physically active on a regular basis, since the best results in hepatic health have been obtained in the longer term, i.e. from 10 weeks of intervention with physical activity.

The biochemical variables related to lipid profile showed a significant difference only for HDL in comparison of insufficiently active and physically active groups $(p=0.02)$. High-density lipoprotein is associated with low risk in development of cardiovascular diseases. The literature shows that the regular practice of physical activity has the capacity to maintain and improve the plasma quantitative levels of this lipoprotein [4, 9]. Surprisingly, the physically active group demonstrated higher levels of HDL in comparisons to both insufficiently active and very physically active groups. Sarzynski et al. evaluated the effect of different exercise modalities in pre-diabetes patients and found that the main factors to improve HDL in the bloodstream are the intensity and duration of exercise [23]. We believe that in our study, the absence of this result in the very physically active group may have been due to factors related to diet and maintenance of body weight [3, 27]; however, this hypothesis cannot be answered since we did not have access to the nutritional assessments of these patients. Other factors that may be associated with this outcome may be related to the changes that occur in the physically active lifestyle in different life cycles, since PA levels tend to decrease throughout 
life in association with the aging process, and this is seen mainly in women [27].

Alkaline phosphatase is used in clinical practice to check for possible hepatic ductal lesions, but it is more related to the onset and development of osteoarticular diseases. Our results showed that the very physically active group maintained lower values of this enzyme. This can be explained by the long exposure to physical activity [23]. Total bilirubin concentration is one of the parameters used in the evaluation of liver function. Higher values of this enzyme suggest disturbances in viscera functioning and/or hepatic parenchyma lesions [14].

Fat accumulation in the abdominal region is associated with increased risk of cardiovascular disease. Higher values of abdomen circumference are associated with moderate or high risk of suffering a cardiovascular event. Analysis of waist, abdomen and chest circumference showed that when exposed to higher levels of physical activity, patients have lower circumference values due to it being the main energy source [15]. In addition, the accumulation of fat in the abdominal region, independent of total fat volume, is a determining factor in the pathogenesis of other hepatic disorders such as NAFLD [2].

We believe that the results obtained in our study, mainly in relation to the anthropometric profile, can be explained by activation of the AMP kinase pathway using energetic substrates used during the regular practice of physical activity. Activation of AMP kinase increases the production of ATP, mainly through the oxidation of free fatty acids and glucose transport. In addition, the decrease of intrahepatic glycogen leads the liver to trigger higher consumption of fat, consequently decreasing its stock [14]. Thus, excess fat, located in the liver, is used to generate energy during and after the practice of physical activities and hence positively regulating the lipid profile and improving the clinical picture of patients. Moreover, AMP kinase is thought to signal expression of peroxisome proliferator-activated receptor-delta to suppress stellate cell proliferation [14].

It is concluded that regular practice of physical activity and variables related to this practice (intensity, frequency and duration) can improve the clinical and anthropometric profile in patients infected with HCV. Moreover, patients who perform more than 300 minutes of physical activity per week can achieve double benefits in the liver such as maintenance of liver enzymes related to hepatic damage and quality of life when compared to those considered insufficiently active. Therefore, the practice of physical activity should be encouraged in this population mainly in individuals who do not have access to antiviral treatments. An important implication of our study is that when other methodologies such as magnetic resonance, dual energy X-ray absorptiometry (DEXA) are not available, anthropometric measures can be used to estimate some features of body composition in patients infected with HCV.
Conflict of interest: Authors state no conflict of interest.

\section{References}

1. Balakrishnan M., El-Serag H.B., Nguyen T., Hilal J., Kanwal F., Thrift A.P. (2017) Obesity and Risk of Nonalcoholic Fatty Liver Disease: A Comparison of Bioelectrical Impedance Analysis and Conventionally-Derived Anthropometric Measures. Clin. Gastroenterol. Hepatol., 15(12): 1965-1967. DOI: doi.org/10.1016/j. cgh.2017.06.030.

2. Chaves G.V., Souza D.S., Pereira S.E., Saboya C.J., Peres W.A.F. (2012) Associação entre doença hepática gordurosa não alcoólica e marcadores de lesão/função hepática com componentes da síndrome metabólica em indivíduos obesos classe III. Rev. Assoc. Med. Bras., 58: 288-293. DOI: $10.1590 / \mathrm{S} 0104-42302012000300007$.

3. Clark J.E. (2015) Diet, exercise or diet with exercise: comparing the effectiveness of treatment options for weight-loss and changes in fitness for adults (18-65 years old) who are overfat, or obese; systematic review and meta-analysis. Journal of Diabetes \& Metabolic Disorders, 14(1): 31. DOI: 10.1186/s40200-015-0154-1.

4. De Sousa Fernandes M.S., e Silva L.dL.S., Santos G.C.J., de Siqueira É.R.F. (2018) Biochemical markers and levels of physical activity related to the hepatic condition of patients infected by the hepatitis $\mathrm{C}$ virus. Biomed. Hum. Kinet., 10(1): 15-18. DOI: 10.1515/bhk-2018-0003.

5. Dong Y., Wang Z., Chen Z., Wang X., Zhang L., Nie J., Zheng C., Wang J., Shao L., Tian Y., Gao R. (2018) Comparison of visceral, body fat indices and anthropometric measures in relation to chronic kidney disease among Chinese adults from a large scale cross-sectional study. BMC nephrology, 19(1): 40. DOI: 10.1186/s12882-0180837-1.

6. E Silva L.dL.S., de Souza Fernandes M.S., de Lima E.A., de Lima R.E., de Moura P.M.M.F. (2018) Physical activity as a protective factor against development of liver steatosis in patients infected with hepatitis C. Biomed. Hum. Kinet., 10: 89-94. DOI: 10.1515/bhk-2018-0014.

7. El-Kader S.M.A., Al-Jiffri O.H. (2018) Impact of weight reduction on selected immune system response among Hepatitis C virus Saudi patients. African Health Sciences, 18(2): 417-427. DOI: 10.4314/ahs.v18i2.27.

8. Gómez-Sánchez L., García-Ortiz L., Recio-Rodríguez J., Patino-Alonso M., Agudo-Conde C., Gómez-Marcos M. (2015) Relationship between physical activity and hemodynamic parameters in adults. Hipertension y riesgo vascular, 32(3): 113-118. DOI: 10.1016/j. hipert.2015.03.002.

9. Gordon B., Chen S., Durstine J.L. (2016) The effects of exercise training on the traditional lipid profile and beyond. Translational Journal of the American College 
of Sports Medicine, 1(18): 159-164. DOI: 10.1249/ JSR.0000000000000073.

10. Haskell W.L., Lee I.M., Pate R.R., Powell K.E., Blair S.N., Franklin B.A., Bauman A. (2007) Physical activity and public health: updated recommendation for adults from the American College of Sports Medicine and the American Heart Association. Circulation, 116(9): 1081. DOI: 10.1249/mss.0b013e3180616b27.

11. Heim M.H., Thimme R. (2014) Innate and adaptive immune responses in HCV infections. J. Hepatol., 61(1): S14-S25. DOI: 10.1016/j.jhep.2014.06.035.

12. Henson J., Edwardson C.L., Morgan B., Horsfield M.A., Bodicoat D.H., Biddle S.J., Gorely T., Nimmo M.A., McCann G.P., Khunti K., Davies M.J., Yates T. (2015) Associations of sedentary time with fat distribution in a highrisk population, DOI: 10.1249/MSS.0000000000000572.

13. Kao C.C., Yi G., Huang H-C. (2016) The core of hepatitis $\mathrm{C}$ virus pathogenesis. Current opinion in virology, 17 : 66-73. DOI: 10.1016/j.coviro.2016.01.009.

14. Kistler K.D., Brunt E.M., Clark J.M., Diehl A.M., Sallis J.F., Schwimmer J.B. (2011) Physical activity recommendations, exercise intensity, and histological severity of nonalcoholic fatty liver disease. Amer. J. Gastroenterol., DOI: 10.1038/ajg.2010.48.

15. Levy G. (2016) Energy and Exercise Part I: Energy Production and Systems. Energy.

16. Matsudo S., Araújo T., Matsudo V., Andrade D., Andrade E., Oliveira L.C., Braggion G. (2012) Questionário Internacional De Atividade Física (Ipaq): Estudo De Validade E Reprodutibilidade No Brasil. Revista Brasileira de Atividade Física \& Saúde, 6(2): 5-18. DOI: 10.12820/ rbafs.v.6n2p5-18.

17. Marfell-Jones M., Olds T., Stewart A., Carter J. (2006) International standards for anthropometric assessment (revised 2006). Underdale, SA: International Society for the Advanced of Kinanthropometry, Links.

18. McKenna O., Blake C. (2007) Management of hepatitis C: the potential benefits of exercise. Physical therapy reviews, 12(4): 271-276. DOI: 10.1179/108331907X223065.

19. Nilsson A., Bergens O., Kadi F. (2018) Physical Activity Alters Inflammation in Older Adults by Different Intensity Levels. Med. Sci. Sports Exerc., DOI: 10.1249/ MSS.0000000000001582.

20. Pellicoro A., Ramachandran P., Iredale J.P., Fallowfield J.A. (2014) Liver fibrosis and repair: immune regulation of wound healing in a solid organ. Nature Reviews Immunology, DOI: 10.1038/NRI3623.
21. Petta S., Maida M., Macaluso F.S., Barbara M., Licata A., Craxì A., Cammà C. (2016) Hepatitis $\mathrm{C}$ virus infection is associated with increased cardiovascular mortality: a meta-analysis of observational studies. Gastroenterology, 150(1): 145-155, e4. DOI: 10.1053/j.gastro.2015.09.007.

22. Pinzani M. (2015) Pathophysiology ofliver fibrosis. Digestive diseases, 33(4): 492-497. DOI: 10.1159/000374096.

23. Sarzynski M.A., Ruiz-Ramie J.J., Barber J.L., Slentz C.A., Apolzan J.W., McGarrah R.W., Harris M.N., Church T.S., Borja M.S., He Y., Oda M.N., Martin C.K., Kraus W.E., Rohatgi A. (2018) Effects of Increasing Exercise Intensity and Dose on Multiple Measures of HDL (High-Density Lipoprotein) Function. Arterioscler. Thromb. Vasc. Biol., 38(4): 943-952. DOI: 10.1161/ ATVBAHA.117.310307.

24. Shephard R.J., Johnson N. (2015) Effects of physical activity upon the liver. Eur. J. Appl. Physiol., 115(1): 1-46. DOI: 10.1007/s00421-014-3031-6.

25. Smart N.A., King N., McFarlane J.R., Graham P.L., Dieberg G. (2016) Effect of exercise training on liver function in adults who are overweight or exhibit fatty liver disease: a systematic review and meta-analysis. Br. J. Sports Med., 52(13): 834-843. DOI: 10.1136/bjsports2016-096197.

26. Varady K.A., Bhutani S., Klempel M.C., Kroeger C.M. (2011) Comparison of effects of diet versus exercise weight loss regimens on LDL and HDL particle size in obese adults. Lipids in health and disease, 10(1): 119. DOI: 10.1186/1476-511X-10-119.

27. Yazbek M.A., Marques Neto J.F. (2008) Osteoporose e outras doenças osteometabólicas no idoso. Einstein, 6(sup 1): S74-S8.

28. Yki-Järvinen H. (2015) Pathogenesis of nonalcoholic fatty liver disease (NAFLD). International Textbook of Diabetes Mellitus, 2: 283. DOI: 10.1002/9781118387658. $\operatorname{ch} 19$.

\section{Received 09.09.2018 \\ Accepted 04.02.2019}

(C) University of Physical Education, Warsaw, Poland 